Article

\title{
Exploring and Sustaining Language Teacher Motivation for Being a Visiting Scholar in Higher Education: An Empirical Study in the Chinese Context
}

\author{
Honggang Liu ${ }^{1}\left(\mathbb{D}\right.$, Lixiang Gao $^{2}$ and Fan Fang ${ }^{3, *(\mathbb{D}}$ \\ 1 Department of English, School of Foreign Languages, Northeast Normal University, Changchun 130024, China; \\ liuhg213@nenu.edu.cn \\ 2 Faculty of Education, Northeast Normal University, Changchun 130024, China; gaolx233@nenu.edu.cn \\ 3 Department of Foreign Languages and Literature, College of Liberal Arts, Shantou University, \\ Shantou 515063, China \\ * Correspondence: ffang@stu.edu.cn
}

Received: 6 July 2020; Accepted: 23 July 2020; Published: 28 July 2020

check for updates

\begin{abstract}
Language teacher motivation has been explored through various contexts in recent decades. However, less attention has been paid to teachers' motivations for furthering their professional development in multilingual academic environments, such as by becoming visiting scholars at top universities at home or abroad. This study adopts a mixed-method approach to investigate language teachers' motivations for being visiting scholars. First, a questionnaire was conducted on 169 teachers who spoke both English and languages other than English (LOTEs). Following an exploratory factor analysis, six separate motivational sources were identified: internal needs, stress relief, academic positioning, academic contact, academic symbolism, and policy support. For triangulation purposes, further interviews were conducted with three visiting scholars and one supervisor for in-depth qualitative data analysis. Interview findings reveal an imbalance between high demand for visiting scholarship funding and the financial allowances granted by governments and universities. Visiting scholars also experience inadequate academic guidance from their supervisors and few opportunities to participate in supervisors' projects. Based on the research findings, this study proposes ways to sustain teacher motivation at the macro (policy) level, the meso (tutor system) level, and the micro (individual supervision) level.
\end{abstract}

Keywords: higher education; language teacher motivation; multilingualism; sustainability of motivation; visiting scholar

\section{Introduction}

Teacher education has long been researched due to the critical roles that teachers play in society. Educating qualified teachers and sustaining their professional development is a top priority for governments and teacher education institutions across the globe. Many policies have been enacted to trigger developmental motivation for higher education teachers, engaging them with different ways to pursue their own personal and professional growth. This includes scholarly visits to prestigious universities [1], participation in academic in-service training [2], and attending high-quality academic conferences [3]. In this paper, "prestigious" or "top" universities refer to the universities that are part of Project 211 or Project 985, or are otherwise considered world-class universities. Project 211 is the Chinese government's new national endeavor aimed at strengthening 100 universities and their key disciplinary areas. Project 985 is a constructive project for founding world-class universities in the 21st 
century (https://www.chinaeducenter.com/en/cedu.php). In November 2015, the Chinese State Council also released a document entitled "Implementation measures to coordinate development of World-class Universities and First-class Disciplines Construction" that explained methods for improving the status and international competitiveness of China's higher education system (https://internationaleducation. gov.au/News/Latest-News/Pages/China-sets-direction-for-world-class-universities.aspx). Due to the policies for getting the funding from either the universities where teachers work or from the Ministry of Education (MoE) of the People's Republic of China, all the applicants for being visiting scholars should choose top (prestigious) universities as the targets. Because such initiatives are often funded by the teachers' home universities or by the MoE, P.R.C., visiting scholar applicants are encouraged to choose prestigious host universities. However, scant attention has been placed on why English teachers and LOTE teachers might choose one program over another in competitive application opportunities. For policymakers and higher education administrators to construct effective frameworks to further sustain teacher motivation in continued professional development, it is particularly beneficial to explore the various reasons why university teachers pursue Visiting Scholar Programs (VSPs) in the first place. Specifically, studying language teachers' motivations for professional development can enrich the general study of teacher motivation, the former of which is yet to be widely explored [4]. To address this research gap, the current study examines the motivations of university language teachers to apply for visiting scholarships at top universities in mainland China, discussing possible solutions for sustaining and developing their motivation for professional development. Adopting both questionnaire and interview as research instruments, this paper aims to unpack visiting teachers' motivations of choosing the programs (through 30 items in the questionnaire), understand the various problems encountered in sustaining teachers' visiting motivations (through three items of the questionnaire and the interview) in order to propose some suggestions for sustaining an ecology-friendly atmosphere for VSPs both in China and abroad. The resulting information will be used to suggest ways of fostering friendly and sustainable VSP experiences both in China and abroad.

In recent years, MoE proposed, supported, and directed a large body of projects, plans, and funding for teachers' professional development. Such programs have greatly furthered the professional growth of teachers from many different backgrounds with positive results. The VSP is one such program in which various teachers can go on leave from their academic appointments at a home institution or at overseas universities to participate in short-term academic projects under the supervision of a host university [5]. The VSPs can be either nationally funded, university and province funded, or university funded only. The visitation period generally lasts between 3-12 months and visiting scholarship locations can be in or out of China.

Every April or May, teachers can apply for a domestic visiting scholarship. Their application documents are given to the Wuhan Center for Teacher Training and Exchange Institution in Higher Education to be administered directly by the MoE for final examination. It is required that domestic visiting scholars be equipped with basic theory and professional knowledge and be able to undertake teaching and academic research independently during the visitation period. Such visiting scholars often obtain senior professional posts, practical experience, and exposure to cutting-edge information in their research fields. After the MoE examinations, teachers are notified of whether they are accepted to the program in July and are asked to start their visitation period in the new semester in September. Every year, more than 1000 teachers from various universities or academic institutions in mainland China are financially supported under this program [1]. VSPs have become an important aspect of continued education for in-service professional development for teachers in China [6].

\section{Literature Review}

Teachers' professional development refers to "the opportunities and activities available for individual teachers" [7] (p. 13). In such educational activities, teachers can enrich their professional knowledge, enhance their professional competence, and enlarge the scopes of their own careers. Their motivations for engaging in different developmental models reflect their orientations towards 
professional in-service education. Drawing on the significance of teachers' individual professional development, the current study aims to investigate university teacher motivation for being a visiting scholar (shortened to "visiting motivation" hereafter), a form of continued education for in-service teachers. Various studies about motivations for participating in continuing education [8-14] have informed the current research. Boshier and his team $[8,9,15]$ conducted large-scale in-depth investigations regarding such education, which inspired the current study to adopt their Education Participation Motivation (EPM) classification as a guiding framework.

\subsection{Education Participation Motivation: Development and Measurement}

Research on EPM began in an empirical study by Houle [16] about learners' motivations for pursuing continuing education programs. In this study, Houle discovered three separate motivations for participating in continued learning: goal-oriented (receiving education as a way of achieving lucid goals), activity-oriented (achieving goals unrelated to study, such as making new friends), and learning-oriented (acquiring more knowledge). This three-dimensional framework became one of the key references for some later studies [9,11,17-20]. In the past five decades, Boshier conducted a series of research to study learners' willingness to participate in continuing education in different contexts, thereby enriching the dimensions of EPM $[9,11,17]$.

Boshier [17] designed the first version of the Education Participation Scale (EPS, F-form) to investigate students' EPM. This EPS consists of 48 items and was administered to 233 adult participants from Wellington, New Zealand, attending continuing education courses. Four factors were yielded from this study, namely other-directed advancement, cognitive interest, self- versus other-centeredness, and social contact. Using the EPS, Boshier [8] replicated the investigation in another group of 242 adult learners in Vancouver, Canada. The exploratory factor analysis (EFA) generated the following five factors: escape/stimulus seeking, professional advancement, social welfare, external expectations, and cognitive interest. Based on these two studies, Boshier and Collins [15] sought to validate EPS (F-form) with a larger sample $(n=12,191)$ in seven countries. It finally confirmed six orientations of continuous learning: social contact, social stimulation, professional advancement, social service, external expectations, and cognitive interest.

Afterwards, Boshier [9] advanced this study by working out an alternative form of EPS (EPS, A-form) and validated it with another large sample $(n=1314)$. An EFA of EPS (A-form) summarized seven motivations that echoed the previous findings. The factors of cognitive interest, social contact, social stimulation, and professional advancement were extended to include communication improvement (improving speaking and writing skills), educational preparation (compensating for previously poor education or preparing for future studies), and family togetherness (bridging generational gaps and improving family relationships). Boshier et al. [11] administered EPS (A-Form) to 448 adults enrolled in Shanghai adult education classes to better understand their motivational orientations to help educators create adult education systems. Seven factors were produced: cognitive interest, social contact, educational preparation, family togetherness, communication improvement, social stimulation, and professional advancement.

\subsection{Application of EPM in Researching Teacher Motivation in Mainland China}

Boshier's studies $[8,11,17]$ concentrate on learners' orientations towards continuous learning in different cultural contexts. Their findings offer inspiration to researchers in the field of teacher education to explore teachers' service-learning motivations in the Chinese context. For example, $\mathrm{Xu}$ and Huang explored the motivations of 737 primary and secondary school teachers for participating in a Master of Education program [21]. The EFA results showcased four motivations: career development (enhancing their professions and potentially securing additional employment), professional growth (enriching knowledge and improving professional skills to better qualify for their jobs), external influences (encouragement from surrounding people and the workplace to continue their postgraduate studies), and competitive advantage (developing an advantage over 
colleagues for professional promotion and posts). Liu and Kou researched scholarly visiting motivation with 182 English teachers from 118 higher education institutions nationwide [1]. Seven factors were extracted: academic positioning (being motivated by a famous university with academic influence), cognitive interest (wanting to improve teaching and research skills), social responsibility (sharing knowledge with colleagues to improve together), academic contact (setting up an academic network with experts and other visiting scholars), academic achievement (publishing articles and applying for projects through postgraduate studies), stress relief (relaxing oneself for improved wellbeing), and competition capital (earning respect or gaining an advantage over others for potential promotions). Echoing the findings from previous studies, Liu and Kou explored EPM in VSP by contextualizing academic features [1], three of which differed from prior findings by Boshier and other scholars: motivations for academic positioning, academic contact, and academic achievement.

Guided by Boshier [9,17], Liu [22] recruited 622 high school and primary school teachers through a questionnaire adapted from Boshier [9] to explore their motivations for pursuing a Master of Education degree. Through EFA, a seven-dimension learning motivation model was constructed as follows: academic information (gaining cutting-edge academic knowledge and teaching materials and receiving expert guidance), competition capital, academic achievement, social responsibility, academic positioning, and cognitive interest. In a similar vein, Liu and Wang examined the attitudes of 155 primary and secondary English teachers about participating in a national training program [23]. The results of EFA identified six motivational factors for teachers to pursue in-service education. These motivations consist of academic positioning, cognitive interest, motivation to obtain competition capital, important influences (e.g., families and leaders), motivations to acquire academic information, and orientations to set up or extend their academic network.

The reviewed literature above unveils two key study features that were inspired by Boshier's EPS, both F-form and A-form. The first feature lies in the numerical changes of the scales' dimensions and items. This change occurred in the 1990s when Boshier completed EPS (A-form) to build on the EPS (F-form) from 1971. During the period in between, various versions of the questionnaires were created, including a 48-item version [8,17], a 40-item version [15], and a 42-item version [9]. Based on these versions, different frameworks of motivation were generated and included 4-7 dimensions. Based on the characteristics and components of the EPS framework at different stages, as well as Boshier's definition of different EPS versions, some critical EPS-related motivational factors can be summarized as follows: Professional Advancement (helping participants achieve lucid goals to improve their profession), Cognitive Interest (gaining knowledge and improving cognition), Social Contact (pursuing broader interpersonal relationships), Social Stimulation (seeking novel stimulation as a form of escapism), Communication Improvement (improving oral and written communication habits), Educational Preparation (compensating for educational inadequacies or preparing for greater professional education), and Family Togetherness (bridging generational gaps and improving family relationships).

The related studies by $\mathrm{Xu}$ and Huang [21], Liu and Kou [1], Liu and Wang [23], and Liu [22] also contributed to this change when EPS was applied in the field of teacher education. This implies that the underlying reasons behind the change may have related to a shift in research focus, contexts, and participants. Boshier's research targeted students' continuous learning, while the studies conducted in China pertained to teachers' professional learning. All these studies had positive implications regarding teachers' motivations for their professional service-learning and development. Being a visiting scholar is a form of service-learning for teachers, as well as a form of adult continuous learning. Although some scholars have touched on the topic of motivation for scholarly visits at top universities [1], expanding research participants and utilizing more valid and contextualized instruments would address an unexplored area of this topic. The current study focuses on the motivations of teachers from different disciplines at mainland Chinese universities in terms of why they participate in VSPs. A major aspect of this research encompasses not only the reasons for teachers 
undertaking visiting scholarships, but also how to sustain these motivations. To address these two issues, the following research questions are addressed:

(1) What are the motivations of language teachers to participate in VSPs?

(2) What are visiting scholars' levels of motivation?

(3) What problems arise in sustaining teachers' visiting motivations?

\section{Methodology}

\subsection{Research Participants}

In total, 169 teachers from 97 universities in four municipalities within three autonomous regions (Ningxia Hui Autonomous Region, Inner Mongolia Autonomous Region, and Guangxi Zhuang Autonomous Region) participated in this research, among whom 28 male teachers and 141 female teachers all had experiences as visiting scholars in the past five years (2016-2019). In total, 141 participants taught English and 28 of them were teachers of LOTEs (e.g., Japanese, Spanish, and Russian). Three visiting scholars and one supervisor, Professor W, were interviewed for further data triangulation.

\subsection{Research Instruments}

Questionnaires and interviews were two major instruments adopted in this study. A 32-item questionnaire explored the types of visiting motivations (items 1-30) and problems the teachers encountered during their visiting scholarships in regard to supervisor guidance (item 31), participation in supervisor projects (item 32). The questionnaire was revised from Boshier's [9] and Liu and Kou's [1] research (see Appendix A). The interviews of the three visiting scholars and one supervisor were supportive in triangulating the questionnaire by examining the problems in teachers' visiting experiences and the solutions to related problems. The interview questions were designed to determine the interviewees' motivations for VSP participation, acquire insight about the problems they had during their visit, and their suggestions for how host universities, policymakers, and home universities can help sustain visiting motivations.

\subsection{Data Collection}

Data collection lasted for five months from November 2018 until March 2019. During this period, questionnaires were circulated via an online questionnaire system called Wenjuanxing to teachers working at universities or colleges. Based on the contact information of the teachers likely to be interviewed at the end of the questionnaire, 10 were purposively selected based on the questionnaire responses and contacted [24]. Three of them agreed to take part in semi-structured interviews [24,25], which were adopted to enhance the researchers' flexibilities to ask key questions [26]. The interviews mainly focused on their reasons for applying to a VSP, their visiting experiences, and their comments about problems with supervisor guidance, frequency of supervision, and whether they joined supervisor projects. We also interviewed a supervisor, Professor W, who was in charge of the VSP at a key university in China. The university in question is a comprehensive university and was among the top 500 universities in the 2018 QS World University Rankings. A Professor of Applied Linguistics in the English department at X University, Professor W, was introduced to the research team by a colleague of the first author. Professor W, who is assigned two to three visiting scholars every year, was interviewed with the view to understanding how he supervises visiting scholars and his feedback about effective visiting scholar supervision. The interview centered on his comments about current VSPs and his suggestions for enhancing VSP quality.

As the interview was adopted to further explore issues in sustaining teachers' visiting motivations, some questions were asked about their specific motivations for being a visiting scholar, problems encountered during their visitation, and suggestions for improving the quality of the visitation 
system. Professor W was asked about policies and faculty support for VSPs, problems based on his own supervision experience, and his suggestions about the host university's system of visiting scholars. All the interviews were carried out in Mandarin so that participants could express their ideas in their native language [27]. Each interview lasted 20-30 $\mathrm{min}$. The interviews were audio recorded, with transcriptions sent to interviewees so they could double-check for accuracy. The participants, who will remain confidential, learned about the research purposes before voluntarily participating in the study. None of the interviewees had contact before the interview and had no conflict of interest with the researchers.

\subsection{Data Analysis}

All quantitative data were recorded in SPSS 24.0. While the questionnaire was designed based on one used to examine English teachers' visiting motivations, teacher motivation remained a mystery when the new and adapted questionnaire was used in a new sample of multilingual teachers. Because of this, EFA was necessary to identify the factor structure of a latent variable, which is done when researchers are uncertain of the number of the latent and observed variables [28]. Principal Axis Factoring (PAF) was selected as the extraction method-it is suitable for identifying underlying factor structure, which can reflect any commonalities the variables share [28].

Qualitative content analysis was adopted in this study [24,29]. The key theme chosen for analysis was "struggles in sustaining teachers" visiting motivations," as per the third research question. It is believed that qualitative content analysis enables researchers "to explore [ ... ] deeper meanings so as to add interpretive depth and breadth to the analysis" [30] (p. 128) through interactive discourse. All the interview data were double-checked and analyzed. Only the interviewees' comments on the problems they had during their visits, as well as Professor W's talks about the VSP system and his related work, were used in this paper to answer the second research question.

\section{Results and Discussion}

\subsection{Results of EFA of the Visiting Motivation Structure}

In response to the first research question, direct oblimin rotation was run when using PAF to rotate the factors. The threshold value of factor loadings was set to 0.30 . The data were suitable for EFA, as indicated by the Kaiser-Meyer-Olkin (KMO) of $0.782\left(\chi^{2}=1146.366, d f=210, p=0.000\right)$. After deleting eight items, eight factors were naturally extracted and cumulatively account for $48.473 \%$ of all variance. All factor loadings were above $|0.40|$ and the eigenvalues of all factors were greater than 1 . The commonality of each item was above 0.20 and the reliability of each factor varied between 0.613 to 0.839 , making the questionnaire more reliable and valid. Dörnyei (2007) suggests the item of each dimension in a structure should be above at least 0.60. (See Table 1).

Factor 1-Internal Needs-encompasses two aspects of visiting motivation. One is related to respondents' cognitive interest in their major and their hopes of improving their "reflective thinking" (Q12) during their visit. They also wish to further clarify the direction of their academic research (Q13). The other orientation relates to teachers' intentions of advancing their own projects (Q10), working on high-quality papers (Q16), and obtaining more cutting-edge academic resources and information (Q11). These two orientations both reflect teachers' visiting motivations rooted in their intrinsic interests [31]. These hopes are all the internal needs of the visiting scholars, hence the name of the factor. This motivation was supported by the findings in Boshier [9,17] and Liu and Kou [1]. These two studies both identified cognitive interests that share similarities with the first orientation of Factor 1 . However, the second orientation of Factor 1 falls under two different motivations in Liu and Kou [1], namely the pursuit of academic products and academic information. One possible reason for this difference may be explained by the extension of samples from English teachers, in Liu and Kou [1], to multilingual teachers. In some academic research, cognitive interests may manifest as getting work published or completing projects. 
Table 1. Results of EFA for Language Teacher Visiting Motivations.

\begin{tabular}{|c|c|c|c|c|c|c|c|}
\hline Excerpts of Items & $\begin{array}{l}\text { Factor } 1 \\
\text { Internal } \\
\text { Needs }\end{array}$ & $\begin{array}{l}\text { Factor } 2 \\
\text { Stress } \\
\text { Relief }\end{array}$ & $\begin{array}{l}\text { Factor } 3 \\
\text { Academic } \\
\text { Positioning }\end{array}$ & $\begin{array}{c}\text { Factor } 4 \\
\text { Academic } \\
\text { Contact }\end{array}$ & $\begin{array}{l}\text { Factor } 5 \\
\text { Academic } \\
\text { Symbolism }\end{array}$ & $\begin{array}{l}\text { Factor } 6 \\
\text { Policy } \\
\text { Support }\end{array}$ & Commo-Nality \\
\hline $\begin{array}{l}\text { Q12 To improve critical } \\
\text { thinking skills. }\end{array}$ & 0.803 & -0.199 & -0.017 & 0.117 & -0.143 & -0.132 & 0.808 \\
\hline $\begin{array}{l}\text { Q13 To enable future } \\
\text { academic development. }\end{array}$ & 0.768 & 0.009 & 0.080 & -0.144 & 0.034 & 0.102 & 0.641 \\
\hline $\begin{array}{c}\text { Q10 To } \\
\text { accomplish projects. }\end{array}$ & 0.704 & 0.051 & -0.146 & 0.057 & 0.042 & -0.094 & 0.496 \\
\hline $\begin{array}{l}\text { Q16 To publish high } \\
\text { quality papers. }\end{array}$ & 0.637 & 0.049 & 0.053 & -0.030 & 0.013 & -0.077 & 0.451 \\
\hline $\begin{array}{l}\text { Q11 To acquire } \\
\text { more updated } \\
\text { academic materials. }\end{array}$ & 0.547 & -0.121 & 0.010 & -0.018 & -0.208 & 0.016 & 0.437 \\
\hline $\begin{array}{l}\text { Q08 To escape scientific } \\
\text { research stress in } \\
\text { the workplace. }\end{array}$ & 0.020 & 0.618 & -0.156 & -0.011 & 0.039 & -0.015 & 0.451 \\
\hline $\begin{array}{l}\text { Q21 To mitigate the } \\
\text { burden of work from } \\
\text { miscellaneous affairs. }\end{array}$ & 0.019 & 0.552 & 0.022 & -0.068 & -0.039 & -0.058 & 0.338 \\
\hline $\begin{array}{l}\text { Q15 To adjust } \\
\text { fatigue/boredom } \\
\text { over teaching. }\end{array}$ & -0.102 & 0.518 & -0.022 & 0.025 & 0.034 & -0.056 & 0.290 \\
\hline $\begin{array}{l}\text { Q18 To curb } \\
\text { teaching stress. }\end{array}$ & 0.024 & 0.503 & -0.028 & 0.022 & -0.197 & 0.134 & 0.343 \\
\hline $\begin{array}{l}\text { Q01 For the renowned } \\
\text { academic status of the } \\
\text { host university. }\end{array}$ & -0.031 & 0.010 & -0.884 & 0.069 & -0.136 & -0.077 & 0.799 \\
\hline $\begin{array}{l}\text { Q02 For the leading } \\
\text { figures at the } \\
\text { host university. }\end{array}$ & 0.041 & 0.153 & -0.821 & -0.061 & 0.045 & -0.048 & 0.762 \\
\hline $\begin{array}{l}\text { Q04 For the host } \\
\text { university's good } \\
\text { academic atmosphere. }\end{array}$ & 0.032 & -0.001 & -0.401 & -0.078 & 0.030 & 0.137 & 0.204 \\
\hline $\begin{array}{l}\text { Q03 To build connections } \\
\text { with experts in } \\
\text { academic fields. }\end{array}$ & -0.057 & -0.010 & -0.144 & -0.682 & -0.031 & -0.093 & 0.512 \\
\hline $\begin{array}{l}\text { Q06 To establish } \\
\text { relationships with } \\
\text { leading figures within the } \\
\text { teaching circle. }\end{array}$ & -0.036 & 0.022 & 0.008 & -0.655 & -0.036 & -0.088 & 0.459 \\
\hline $\begin{array}{l}\text { Q14 To establish } \\
\text { relationships with } \\
\text { leading figures within the } \\
\text { academic circle. }\end{array}$ & 0.420 & 0.077 & 0.084 & -0.635 & -0.017 & 0.238 & 0.738 \\
\hline $\begin{array}{l}\text { Q17 To be thought highly } \\
\text { of as a visiting scholar. }\end{array}$ & 0.018 & 0.078 & -0.061 & 0.023 & -0.627 & -0.020 & 0.434 \\
\hline Q09 To gain a promotion. & 0.050 & -0.055 & -0.001 & 0.009 & -0.545 & -0.137 & 0.346 \\
\hline $\begin{array}{l}\text { Q20 It is an honor to be a } \\
\text { visiting scholar. }\end{array}$ & 0.003 & 0.084 & 0.014 & -0.110 & -0.537 & 0.151 & 0.360 \\
\hline $\begin{array}{l}\text { Q05 National policies } \\
\text { support the } \\
\text { visiting scholars. }\end{array}$ & 0.084 & -0.186 & -0.012 & -0.269 & -0.114 & -0.563 & 0.528 \\
\hline $\begin{array}{l}\text { Q19 Our department } \\
\text { supports } \\
\text { visiting scholars. }\end{array}$ & 0.176 & 0.125 & 0.108 & 0.015 & 0.060 & -0.466 & 0.317 \\
\hline $\begin{array}{l}\text { Q07 Our school supports } \\
\text { visiting scholars. }\end{array}$ & 0.066 & 0.228 & 0.112 & -0.178 & -0.189 & -0.443 & 0.466 \\
\hline $\begin{array}{c}\text { Percentage of } \\
\text { explained variance }\end{array}$ & 19.827 & 32.161 & 37.771 & 41.895 & 45.274 & 48.473 & - \\
\hline Eigenvalues & 4.165 & 3.038 & 1.658 & 1.363 & 1.304 & 1.152 & - \\
\hline Reliability of each factor & 0.839 & 0.655 & 0.646 & 0.735 & 0.613 & 0.623 & - \\
\hline
\end{tabular}

Factor 2 speaks to teachers' desires to relieve themselves from teaching and research burnout in their own workplaces. It is thus called Stress Relief, a theme that is also highlighted in Boshier [9] and Lee and Peng's [32] findings. The participants of the previous two studies expressed that they wanted to escape unpleasant situations by means of education. This motivation is also found in domestic research, such as Wang et al.'s [33] and Liu and Kou's [1] studies. Visiting scholars are often on visiting 
leave for 6-12 months, during which they have less work as they do before they do their scholarly visit, and they can arrange their own life on their own rights. The pace of life becomes slower and more comfortable, so they may possibly escape from the hard work $[9,17]$. Language teacher development should not focus merely on academic production, but also on psychological wellbeing [34].

Factor 3-Academic Positioning - points to the effects of visiting situations, such as the reputation of host universities or institutions, on teachers' visiting motivation. This factor highlights how environment has a positive effect on teachers' motivations for scholarly visits. Motivation is a socially and contextually-dependent variable [35] and its birth is never separate from someone's circumstances [36]. Being a visiting scholar at a host institution may offer teachers key resources for their academic research and foster invisible capital (e.g., fame, academic environment), which can bring them other benefits in their professional development. Similar findings on language learning motivations also offer support for this factor. Dörnyei proposed that situational components in motivation, such as teachers, course materials, and other learning environments, will facilitate learners' motivations [37]. In the study by Gao et al., they discovered "situational motivation" in tertiary students' English learning [38]. In the interviews, all teachers expressed that they chose host universities based on their fame, and possibly their advanced hardware and software.

Factor 4-Academic Contact—relates to teachers' motivations to set up and extend social networks by doing visiting scholarships. In scholarly visiting, teachers hope to make academic exchanges with other visiting scholars and experts in their own fields. In these exchanges, they are likely to obtain more knowledge and enlarge their horizons, which will sustain and develop their own teaching and academic capacities. These exchanges can also assist teachers in extending their social networks with prestigious experts. This finding is supported by Boshier's "social contact" orientations $[8,9,17]$. In these studies, adults participate in education for building close relationships with others. Similar motivation is also discovered in Liu and Kou, which suggests that teachers desire contact with experts and want to help their workplaces cooperate with VSPs [1].

Factor 5-classified as Academic symbolism—consists of five items related to teachers' expectations to obtain capital by doing a visiting scholarship. Such capital can benefit them by earning them respect from colleagues and students, or to help them meet the requirements of a professional promotion (some universities require applicants to have been visiting scholars at top universities for 6 to 12 months), or even to facilitate their upward mobility of being leaders. To this end, visiting scholar experiences become symbolic capital [39] for teachers, who often think it is an honor to be a visiting scholar. Such experiences and beliefs are useful for teachers' sustainable development. This finding resonates with Liu and Kou's research where teachers with visiting experiences aim to gain competitive advantages over others and improve their status in their workplaces [1].

Factor 6-highlights external support from governments or schools offered to visiting scholars to improve the visiting experiences, which is referred to as Policy Support. National or local policies guarantee visiting scholars enough financial support; moreover, the home universities or departments of visiting scholars are likely to provide such allowances as full salary, extra bonuses, and more to facilitate teachers' scholarly visits. All the items in this factor foreground the importance of policy in supporting teacher's academic visits. This factor is similar to Liu and Wang's finding that national policy makes it convenient for in-service teachers to participate in continuing education [23].

Six types of motivation have been identified in this study, which differs slightly from Liu and Kou's study where academic information (for instance, to acquire more updated academic materials) was not defined as a factor [1]. In addition, though academic contact is similar to the notion of social contact raised by Boshier [40], the former suggests that visiting scholars gain social capital by establishing connections with experts in an academic context so that cultural and academic capital can be gained. However, important others are not detailed as factors in this study, which indicates that teachers of higher education have families or friends holding them back from making certain choices. They are expected to have self-regulation and autonomy [41], deciding whether to be visiting scholars according to their own needs. In this study, "competition capital" refers to items describing teachers' efforts 
to win respect from others, a topic neglected in Liu and Kou's research [1]. Such symbolic capital is inconvertible to factors that influence professional promotion, which may partially account for teachers' weaker drives to gain competition capital.

\subsection{Levels of Visiting Motivations}

The data analysis in this section aims to answer the second research question: "What are visiting scholars' levels of motivation?". This study, in reference to self-determination theory (SDT) [31,42], found that the intrinsic and extrinsic orientations of human behaviors hold that teachers expect to be visiting scholars for these two major orientations, although we recognize the complexity of motivation. They can acquire rich academic information and get inspiration from supervisors and prestigious experts and improve their academic competence. Meanwhile, teachers will have an inner sense of enhancing their knowledge. Moreover, when confronted with burnout, teachers will actively resort to looking for solutions to cope with the stressors [43-45]. Our research participants indicated they prefer to engage in VSPs to readjust themselves and maintain sustainable development. All of the above can be categorized under two internal motivation factors: internal needs and stress relief. However, there are also external reasons as to why teachers choose to be visiting scholars. They may expect to win respect and gain symbolic capital or establish academic connections with experts. They are also motivated to take part in VSPs under the support of different policies from their home university/faculty or from the government. All these are categorized into four external motivations, namely policy support, academic contact, academic symbolism, and academic positioning. (See Table 2).

Table 2. Distributive Statistics for Visiting Motivations.

\begin{tabular}{ccccc}
\hline & Max & Min & M & SD \\
\hline Intrinsic Motivation & 5.78 & 2.70 & 4.06 & 0.61 \\
Internal Needs & 6.00 & 3.40 & 5.25 & 0.65 \\
Stress Relief & 5.75 & 1.00 & 2.85 & 1.07 \\
Extrinsic Motivation & 5.83 & 2.33 & 4.24 & 0.58 \\
Policy Support & 6.00 & 2.33 & 5.16 & 0.61 \\
Academic Contact & 6.00 & 1.67 & 4.39 & 0.88 \\
Academic Symbolism & 6.00 & 1.00 & 3.86 & 0.90 \\
Academic Positioning & 6.00 & 1.00 & 3.56 & 1.31 \\
Motivation in General & 5.75 & 2.92 & 4.15 & 0.51 \\
\hline
\end{tabular}

Overall, teachers are strongly motivated to become visiting scholars $(M=4.15 ; S D=0.51)$. Their intrinsic and extrinsic motivations are both relatively high, although teachers' intrinsic motivations $(M=4.06 ; S D=0.66)$ appear weaker than their extrinsic ones $(M=4.24 ; S D=0.58)$. For the rankings of the six motivational factors in terms of their means, internal needs $(M=5.25 ; S D=0.65)$ leads in first place, followed by policy support $(M=5.16 ; S D=0.61)$, academic contact $(M=4.39 ; S D=0.88)$, academic symbolism $(M=3.86 ; S D=0.90)$, academic positioning $(M=3.56 ; S D=1.31)$, and stress relief $(M=2.85 ; S D=1.07)$. Being a visiting scholar is a complex way to improve oneself, with the primary driver of said improvement being enhanced research skills—during their visits, most teachers focus their attention on research-related issues. To some extent, their visit becomes a journey of doing research in a new ecology. VSP research trips are thus often driven by external factors. This was partially echoed by Peng and Gao in their exploration about the relationship between research motivation and research production [46], which revealed that academics largely do research for external reasons. Although there are differences between the current study and Peng and Gao's [46] in terms of questionnaire structure and basic research framework, they both showcase the importance of policy support, extending social and academic networks, the pursuit of self-relaxation, and symbolic capital in teachers' visiting motivations.

Internal needs and policy support stand out as two dominant types of motivation. This shows that teachers' main visiting motivations stem from their cognitive interests in their own research fields. 
This accords with Boshier who revealed cognitive interest as a primary goal and among the most intense drivers for adults to continue their education [9,17]. It also confirms the findings in Liu and Kou that detail how obtaining academic information and academic achievement are two major motivators for English teachers' domestic visits [1]. Policy support is a newly identified form of motivation, which strongly mirrors the influence of government and university policies on teachers' academic visiting.

It is worth noting that competition capital exhibits lower scores as a factor, which is similar to Liu and Kou's research [1] but slightly distinct from Xu and Huang's [21]. The latter found that primary and secondary teachers exhibited greater desires for competition capital in their pursuits of a Master of Education degree. This may be explained by the lesser role of scholarly visits in non-degree education and its lack of necessity in professional promotion. Teachers' desires to relieve themselves of stress was the last of the motivation rankings, which supports our analysis above that being a visiting scholar is a journey in which research is the major goal.

\subsection{Struggles and Problems in Sustaining Teachers' Visiting Motivations}

From the results and discussions about the types of visiting motivations, it is apparent that teachers have strong motivations in general to participate in VSPs. However, the problems that visiting teachers articulated in their questionnaires have prompted an analysis and a proposal of possible solutions. To better understand the issues in sustaining teachers' visiting motivations, interviews were conducted with three teachers and one supervisor.

The first problem voiced in the interviews was the large demand for acquiring financial resources for scholarly visits paired with limited affordances from governments and universities. Teacher A explained this in his interview:

"I am from a local university in Guizhou, a far western province in China. Thanks to government support, some teachers can succeed in obtaining the funding to stay at a top university. However, I hope more investments can come from the government to local universities in underdeveloped western areas, since there are still more teachers who have strong desires to advance themselves professionally but have no funding to help them do so. Some of my colleagues who perform well and are highly motivated to do research are still waiting for funding". (Teacher A, Associate Professor of English Education, March 2019).

The hope of increased support quotas expressed by Teacher B was also articulated by the LOTE teacher:

"I teach German, which is open to all students from different faculties at my university. I feel that more focus has been placed on LOTEs, like German from both basic education and higher education policies. However, compared to English teachers, we have our own disadvantages such as limited journals for publishing research and few conferences on the topic of German Education. There is very tight competition for getting opportunities to further our education at top universities by doing scholarly visits, for example. We have to join this battle to "fight against" the English teachers ... it's hard ... I hope more special plans can be designed for LOTE teachers in terms of funding and applying for scholarly visits". (Teacher B, German Language Lecturer, December 2018).

Teacher B's excerpt conveys the mismatch in policy for supporting minor languages and the professional development of their respective teachers. The findings of motivational levels above indicate that participants ranked policy support the lowest form of motivation, which partially mirrors the imbalance of support needs and limited supplies. This inadequacy of supply may demotivate teachers from seeking policy support.

The second problem concerns guidance from the tutors. Item 32 displays that $55.1 \%$ of teachers have reported a lack of opportunity to participate in tutor-organized projects. Item 31 conveys that 
$60.4 \%$ participants complained of a lack of guidance from their tutors. These findings contrast negatively with teachers' high motivations to obtain guidance from their tutors. The following interview with a visiting scholar offers some factual support on this quantitative finding:

“To get my academic research supervised is a key goal of my visiting scholarship. I sent my proposal to my supervisor and got his timely feedback, but it seems he is too busy for face-to-face conversations about how to move my research forward. I am poor in research methods in applied linguistics, and I hope to get answers from my supervisor personally. But I was declined several times due to his busy schedule. I find that he is always busy talking to his own MA or PhD students during short breaks between classes, but I am not involved in those interactions. I am a bit disappointed by it". (Teacher C, Associate Professor of English, March 2019).

Teacher $\mathrm{C}$ expressed great disappointment in his lack of personal academic communication with his proposed tutor, despite trying to reach out several times. Not only do Teacher $C$ and the tutor have mismatched timetables, but the tutor's time is fully devoted to his own $\mathrm{PhD}$ or Masters students, regardless.

From the interview with Professor W, we can find an alternate view of this problem:

"To be honest, I want to be able to give the one-to-one supervision I do to my MA or PhD students to the visiting scholars, but I have no time to do that. I am required to accept two visiting scholars every year since the policy only allows a full professor to be a supervisor for visiting scholars. In our department, only five professors can do this, but we have more than 10 visiting scholars to host. It means we five professors will supervise more than two scholars every year. I have many things to do officially and academically; I have no extra time for the visiting teachers". (Professor W, Professor of Applied Linguistics, January 2019).

\section{Implications}

The results of the interviews and questionnaires indicate that visiting scholars experienced some difficulties in obtaining regular and timely one-on-one supervision from their tutors and found few opportunities to take part in their projects. The interview data highlight high demand for being supported as a visiting scholar and point to inadequate affordances from universities, local government education bureaus, and the MoE. Knowing that teachers have generally strong incentives to participate in VSPs from all defined perspectives (except in terms of policy support), how to maintain their motivation to pursue these programs becomes an important question for not only policymakers, but also administrators at host and home institutions. While Liu and Kou [1] and Wang et al. [47] highlight better teacher training and more supportive polices as being beneficial to teachers' pursuits of VSPs, few strategies have been detailed for putting these benefits into practice. We therefore propose a new ecology to trigger and sustain teacher motivation.

At the macro policymaking level, it is recommended that financial support should be continuously rendered to teachers in higher education, which will highly sustain the teachers' motivation of policy support and their general visiting motivation. The past three decades saw a steady increased investment in supporting teachers as visiting scholars at top universities both within and outside of China. Relevant policies postulated by the Ministry of Education and the Chinese Scholarship Council (CSC) encouraged teachers in higher education to make academic visits, under their financial support, to top universities in and out of China. They enacted special policies, including the Special Support Plan for Western Areas to encourage making scholarly visits to the western part of China. In addition, universities have their own special funding to offer teachers support. These policies play positive roles in teachers' professional development. It is suggested that these policies continue to give more attention to LOTE teachers who are interested in academic achievements [48] but need practical guidance. In support of LOTE teachers to visit top universities in mainland China, the CSC 
launched a special plan supporting them to pay scholarly visits to top universities outside of China, as well. However, few similar plans are designed for domestic visits for teachers in other fields. It seems necessary to create special funding initiatives for LOTE teachers' domestic visits, since this is an effective way to maintain and develop visiting motivations for sustained professional development.

At the meso-level, more effective measures could be taken to construct higher-quality tutor systems at host universities. Voices from both visiting scholars and the tutor serve as reminders that adjustments to the tutorial system are required, as there are too few supervisors to support the number of incoming visiting scholars. Based on the data in this research, the following actions are recommended: First, host institutions should delimit supervisor requirements and allow responsible teachers with high academic abilities with "lower" titles (associate professors, lecturers, or senior lecturers with PhD degrees) to supervise visiting scholars. These supervisors are expected to have fruitful academic achievements and can therefore support visiting scholars. Second, the Dual-Tutor system can be used to involve more capable "low" title teachers in supervisory roles. In the above interviews, it is apparent that busy schedules and overwork cause supervision problems for visiting scholars. In the proposed Dual-Tutor system, lecturers with good academic backgrounds can serve as a second supervisor for visiting scholars when the chief supervisor's schedule does not permit an active supervisory role. In this plan, visiting scholars can benefit from interactions with their tutors, and their motivations for visiting can be largely maintained. The third suggestion applies to the administration departments of host institutions in terms of guidance for visiting scholars. For instance, in the application stage, it would be better if the host university outlined all available supervisors, particularly qualified associate professors or lecturers if the system permits them to tutor visiting scholars. The interview data revealed that some applicants with high academic positioning orientation, such as experiencing and studying at a prestigious university, have no clear understanding of how to select tutors with mutual interests. If supervisor selection could be offered in a more timely manner, visiting scholars would have more fruitful experiences and their motivations for being visiting scholars could be largely sustained. The construction of the higher-quality tutor system will reciprocally sustain teachers' motivations of academic positioning, academic symbolism, academic contact and internal needs, because all these motivations share the commonalities of depending on the ecological systems.

At the micro level, it is advised that visiting scholars obtain more opportunities to participate in supervisor projects and obtain direction about how to conduct research. Being involved in a project is a way of cultivating visiting teachers' academic abilities, and the dialogic interactions during such engagements can largely enhance the professional development of language teachers [49]. The interviews found that some teachers do not know how to plan their visits. Therefore, it is key that ice-breaking meetings are held upon visiting scholars' arrival. Such activities may invite tutors or outstanding MA or PhD candidates to share their research experiences and ideas about doing academic research. PhD candidates can also be encouraged to deliver lectures to visiting scholars about their learning experiences. This kind of "centralized guidance" is best suited to tutors with a major focus on academic knowledge and can make visiting scholars' learning more efficient, thereby diversifying visiting motivations. The visiting scholars achieved higher intrinsic motivation in this study (see Table 2), and these measures above will bring corresponding support to maintain their motivation of internal needs.

\section{Conclusions}

The current study contextualized Boshier's EPM framework in terms of language teacher participation motivations and devoted itself to enriching prior studies on English teachers' visiting motivations, thereby extending the findings of EPM research. Being a visiting scholar is a meaningful activity in a teacher's professional development; maintaining and further empowering their motivations to involve themselves in this contextualized process is challenging, but closely related to teachers' professional development. The current study examined this issue via quantitative findings. Six motivational orientations (internal needs, stress relief, academic positioning, 
academic contact, academic symbolism, and policy support) emerged and showed some similarities and differences between prior studies. The newly-emerged Internal Need factor integrates cognitive interests $[1,8,9,17,22]$ with academic achievement interests [1,22], as well as motivation to obtain academic information [1].

Another new finding, the Policy Support factor, points to increasing attention on language teacher development from governments and universities. In this globalized world, multilingual capacity is a substantial concern in training students at different levels; as such LOTE teacher development should be emphasized. With support from different resources in terms of policy, language teachers can be motivated to do domestic visits at top universities and high-level faculties in China, and their time spent there will then reciprocally support their development.

Although this research endeavored to offer a comprehensive focus on teacher motivation, it possesses some limitations. Both the interview and questionnaire sample sizes were slightly small, and the interviews have yet to be expanded upon. It is recommended that future studies enlarge the research scope and sample and validate the questionnaires used in this study to enrich the findings in teacher motivation research. There is also a gender imbalance in the current study's sample; future research should select more male teachers and note the potential statistical bias caused by this gender imbalance. In addition, it is suggested that more methods, such as ethnographic approaches and narrative approaches, should be used in future research to assess the processes that help form visiting scholarship motivation. Practically speaking, it is hoped that more action can be taken to trigger and maintain teachers' motivations to become visiting scholars. In future research, more studies should focus on how visiting scholarship motivations change before, during, and after teachers' scholarly visits, as well as how these motivations relate to psychological variables (e.g., identity, anxiety, and general well-being). By constructing the ecological support system to benefit more visiting scholars, further research can determine how visiting scholars learn at host universities, interact with teachers from other institutions, and come to terms with their new surroundings. While individual teachers are the center of VSPs at the micro level, it is worth exploring how teachers themselves contribute to the systems that support their VSP experiences. We have found that environmental influences on visiting scholars, such as inadequate supervision and few opportunities to assist in supervisors' projects at the meso level, are key determinants of visiting scholar satisfaction. However, we know less about how visiting scholars contribute to their environments as agents with multiple identities as both teachers and students. In the future, in-depth qualitative research should be conducted to explore visiting scholars' interactions with their newfound environments and identify more positive ways of improving VSPs as a whole.

Author Contributions: Conceptualization, H.L. and L.G.; Methodology, H.L. and F.F.; Data collection, H.L. and L.G.; Formal analysis, H.L., L.G. and F.F.; Writing—original draft preparation, H.L. and L.G.; Writing-review and editing, H.L., L.G. and F.F.; Supervision, H.L.; Funding acquisition, H.L. All authors have read and agreed to the published version of the manuscript.

Funding: This work was supported by the National Social Science Foundation of China titled 'Research on the construction of the ecological model of university foreign languages teachers' motivations for professional development and relevant influencing factors' (Grant Number 15BYY099); and the Project of Discipline Innovation and Advancement (PODIA)-Foreign Language Education Studies at Beijing Foreign Studies University (Grant number: 2020SYLZDXM011).

Acknowledgments: We would like to express our gratitude to Dr. Xuesong Gao and Dr. Yawen Han for their consistent support for this work. We would also like to thank the anonymous reviewers for their constructive comments on earlier draft of this manuscript. Any remaining errors are our own.

Conflicts of Interest: The authors declare no conflicts of interest regarding the publication of this paper.

\section{Appendix A. Items in the Questionnaire}

$$
\begin{aligned}
& 1=\text { totally disagree } \\
& 2=\text { disagree } \\
& 3=\text { somewhat disagree }
\end{aligned}
$$


$4=$ somewhat agree

$5=$ agree

$6=$ strongly agree

Q1 I came here as a visiting scholar because of the host university's reputation and influence.

Q2 I came here as a visiting scholar to meet the leading figures who teach at the host university.

Q3 Being a visiting scholar enables me to build connections with academic experts, which will benefit my academic development.

Q4 I came here as a visiting scholar for the host university's positive academic atmosphere.

Q5 I signed up for VSPs because they are supported by national policies.

Q6 I want to establish relationships with those who excel in teaching for future experience-sharing opportunities.

Q7 I signed up for the VSP because our school supports it.

Q8 Scholarly visits have helped me mitigate research-related stress in the workplace.

Q9 Experiences as visiting scholars are intended to assist in professional promotions.

Q10 Being a visiting scholar will lead to greater achievements in my research projects.

Q11 One of my reasons for becoming a visiting scholar is acquiring more up-to-date academic material.

Q12 I will improve my critical thinking skills as a visiting scholar.

Q13 Experiences as a visiting scholar enable me to make clear future academic development decisions.

Q14 I want to establish relationships with leading figures in academic research (e.g., PhD candidates).

Q15 I want to curb my fatigue/boredom with teaching through visiting scholar experiences.

Q16 I chose to become a visiting scholar to publish high quality papers.

Q17 I will be thought highly of as a visiting scholar.

Q18 I will reduce teaching stress in my workplace as a visiting scholar.

Q19 I signed up for VSPs because our department supports it.

Q20 It is an honor to be a visiting scholar.

Q21 My experiences as a visiting scholar will mitigate the burden of work.

Q22 Being a visiting scholar is a crucial step for me.

Q23 I came here as a visiting scholar to take advantage of the abundant resources related to my major.

Q24 I came here as a visiting scholar for expert academic guidance.

Q25 As a visiting scholar, I will broaden the horizons of my teaching practice.

Q26 I chose to become a visiting scholar to apply for projects at the provincial and national levels.

Q27 My experiences as a visiting scholar have helped me establish prestige and be a role model for students.

Q28 I chose to become a visiting scholar for more cutting-edge academic experiences.

Q29 I signed up for VSPs to pursue opportunities offered by host universities and my own university.

Q30 As a visiting scholar, I will bridge the relationship between the host institution and my home institution

$1=$ not my situation at all

$2=$ not my situation

$3=$ somewhat not my situation

$4=$ somewhat my situation

$5=$ my situation

$6=$ totally my situation

Q31 I was permitted to join my tutor's research project

Q32 I seldom got my tutor's supervision during my visit 


\section{References}

1. Liu, H.; Kou, J. An empirical research on university English teachers' motivations to participate in the “Visiting Scholar Program". Foreign Lang. Their Teach. 2014, 6, 13-19.

2. Tao, J.; Gao, X. Teacher agency and identity commitment in curricular reform. Teach. Teach. Educ. 2017, 63, 346-355. [CrossRef]

3. Borg, S. The benefits of attending ELT conferences. ELT J. 2015, 69, 35-46. [CrossRef]

4. Han, J.; Yin, H. Teacher motivation: Definition, research development and implications for teachers. Cogent Educ. 2016, 3, 1-18. [CrossRef]

5. Ministry of Education of the People's Republic of China, General Office of the Ministry of Education Notice of Implementing the Domestic Visiting Scholar Programme for the Excellent Young Teachers in Higher Education. 2000. Available online: http://www.moe.gov.cn/s78/A04/s7051/201001/t20100129_180802.html (accessed on 20 May 2020).

6. Chen, P. The current situation and solutions of the management of domestic visiting scholars. J. Teach. Res. Chin. Univ. 2011, 24, 7-10.

7. Freeman, D. Arguing for a knowledge-base in language teacher education, then (1998) and now (2018). Lang. Teach. Res. 2020, 24, 5-16. [CrossRef]

8. Boshier, R. Motivational orientations re-visited: Life-space motives and the education participation scale. Adult Educ. Q. 1977, 27, 89-115. [CrossRef]

9. Boshier, R. Psychometric properties of the alternative form of the education participation scale. Adult Educ. Q. 1991, 41, 150-167. [CrossRef]

10. Burgess, P. Reasons for adult participation in group educational activities. Adult Educ. Q. 1971, $22,3-29$. [CrossRef]

11. Boshier, R.; Huang, Y.; Song, Q.; Song, L. Market socialism meets the lost generation: Motivational orientations of adult learners in Shanghai. Adult Educ. Q. 2006, 56, 201-222. [CrossRef]

12. Boeren, E. Profiles and motives of adults in Flemish continuing higher education. Eur. J. High. Educ. 2011, 1, 179-191. [CrossRef]

13. Lee, P.L.; Pang, V. The influence of motivational orientations on academic achievement among working adults in continuing education. Int. J. Train. Res. 2014, 12, 5-15. [CrossRef]

14. Xiong, J.; Zuo, M. Older adults' learning motivations in massive open online courses. Educ. Gerontol. 2019, 45, 82-93. [CrossRef]

15. Boshier, R.; Collins, J.B. Education participation scale factor structure and socio-demographic correlates for 12,000 learners. Int. J. Lifelong Educ. 1983, 2, 163-177. [CrossRef]

16. Houle, C.O. The Inquiring Mind: A Study of the Adult Who Continues to Learn; University of Wisconsin Press: Madison, WI, USA, 1961.

17. Boshier, R. Motivational orientations of adult education participants: A factor analytic exploration of Houle's typology. Adult Educ. Q. 1971, 21, 3-26. [CrossRef]

18. Sheffield, S.B. The orientations of adult continuing learners. In The Continuing Learner; Solomon, D., Ed.; Center for the Study of Liberal Education for Adults: Chicago, IL, USA, 1964; pp. 1-22.

19. Hossain, J. Professional development of higher education teachers: Can ODL contribute? Turk. Online J. Distance Educ. 2010, 11, 123-133.

20. Keefe, D. The Boshier's education participation scale factors reflected in history: Adult motivations to learn in the 19th American Chautauquan movement compared to those of the 21st century Boshier education participation scale. In Handbook of Research on Education and Technology in a Changing Society; Wang, V.X., Ed.; IGI Global: Hershey, PA, USA, 2014; Volume 2, pp. 1151-1160.

21. Xu, F; Huang, W. A study on primary and secondary school teachers' motivations to participate in education master (EdMA) programme and their efficiency. J. Teach. Manag. 2005, 37-39.

22. Liu, H. A quantitative research on English major-free-normal graduates' motivations to participate in education master (EdMA) programme. Acad. Degrees Grad. Educ. 2015, 1, 52-58.

23. Liu, H.; Wang, X. An empirical study on primary and secondary school English teachers' in-service learning motivations: Evidence from “National Teacher Training Program (NTTP)". Engl. Teach. Res. Notes 2014, 11, 50-56. 
24. Dörnyei, Z. Research Methods in Applied Linguistics: Quantitative, Qualitative and Mixed Methodologies; Oxford University Press: Oxford, UK, 2007.

25. Kvale, S.; Brinkmann, S. Interviews: Learning the Craft of Qualitative Research Interviewing, 3rd ed.; SAGE: Newbury Park, CA, USA, 2014.

26. Richards, K. Qualitative Inquiry in TESOL; Palgrave Macmillan: New York, NY, USA, 2003.

27. Mann, S. A Critical Review of Qualitative Interviews in Applied Linguistics. Appl. Linguist. 2011, 32, 6-24. [CrossRef]

28. Hair, J.F.; Black, W.C.; Babin, B.J.; Anderson, R.E.; Tatham, R.L. Multivariate Data Analysis, 6th ed.; Pearson Prentice Hall: Upper Saddle River, NJ, USA, 2006.

29. Schreier, M. Qualitative Content Analysis in Practice; SAGE: Newbury Park, CA, USA, 2012.

30. Jenkins, J. English as a Lingua Franca in the International University: The politics of Academic English Language Policy; Routledge: Oxford, UK, 2014.

31. Deci, E.L.; Ryan, R.M. Intrinsic Motivation and Self-Determination in Human Behavior; Plenum Press: New York, NY, USA, 1985.

32. Lee, P.L.; Peng, V. Motivational factors in continuing education an academic achievement of adult learners. Malays. J. Learn. Instr. 2013, 10, 57-77.

33. Wang, X.; Zhao, C.; Zhou, Y. A study on foreign language teachers' development: Problems and solutions. J. Beijing Int. Stud. Univ. 2006, 26, 75-79.

34. Hofstadler, N.; Babic, S.; Lämmerer, A.; Mercer, S.; Oberdorfer, P. The ecology of CLIL teachers in Austria-An ecological perspective on CLIL teachers' wellbeing. Innov. Lang. Learn. Teach. 2020, 1-15. [CrossRef]

35. Turner, J.C.; Patrick, H. How does motivation develop and how does it change? Reframing motivation research. Educ. Psychol. 2008, 43, 119-131. [CrossRef]

36. Schunk, D.H.; Meece, J.R.; Pintrich, P.R. Motivation in Education: Theory, Research, and Applications, 4th ed.; Pearson: Hoboken, NY, USA, 2004.

37. Dörnyei, Z. Motivation and motivating in the foreign language classroom. Mod. Lang. J. 1994, 78, 273-284. [CrossRef]

38. Gao, Y.; Zhao, Y.; Cheng, Y.; Zhou, Y. Relationship between English learning motivation types and self-identity changes among Chinese students. Tesol Q. 2007, 41, 133-155.

39. Bourdieu, P. The forms of capital. In Handbook of Theory and Research for the Sociology of Education; Richardson, J., Ed.; Greenwood: Westport, CT, USA, 1986; pp. 241-258.

40. Boshier, R.; Collins, J.B. The Houle typology after twenty-two years: A large-scale empirical test. Adult Educ. Q. 1985, 35, 113-130. [CrossRef]

41. Oates, S. The importance of autonomous, self-regulated learning in primary initial teacher training. Front. Educ. 2019, 4, 1-8. [CrossRef]

42. Ryan, R.M. (Ed.) The Oxford Handbook of Human Motivation, 2nd ed.; Oxford University Press: Oxford, UK, 2019.

43. Carlson, B.C.; Thompson, J.A. Job burnout and job leaving in public school teachers: Implications for stress management. Int. J. Stress Manag. 1995, 2, 15-29. [CrossRef]

44. Kamtsios, S. Burnout syndrome and stressors in different stages of teachers' professional development: The mediating role of coping strategies. Hell. J. Psychol. 2018, 15, 229-253.

45. Ugwoke, S.C.; Eseadi, C.; Onuigbo, L.N.; Aye, E.N.; Akaneme, I.N.; Oboegbulem, A.I.; Ezenwaji, I.O.; Nwobi, A.U.; Nwaubani, O.O.; Exegbe, B.N.; et al. A rational-emotive stress management intervention for reducing job burnout and dysfunctional distress among special education teachers. Medicine 2018, 97, 1-8. [CrossRef] [PubMed]

46. Peng, J.; Gao, X.A. Understanding TEFL academics' research motivation and its relations with research productivity. Sage Open 2019, 9, 1-13. [CrossRef]

47. Wang, X.; Zhao, C.; Zhou, Y. Issues and Solutions on researching the foreign language teacher development: Evidence from the investigation of Domestic Visiting Scholar Programme. J. Beijing Int. Stud. Univ. 2006, 8, 75-79.

48. Han, Y.; Gao, X.; Xia, J. Problematising recent developments in non-English foreign language education in Chinese universities. J. Multiling Multicult. Dev. 2019, 40, 562-575. [CrossRef]

49. Johnson, K.E. Reclaiming the relevance of L2 teacher education. Mod. Lang. J. 2015, 99, 515-528. [CrossRef] 